\title{
Transcriptional regulation by p53: one protein, many possibilities
}

\author{
O Laptenko ${ }^{1}$ and C Prives ${ }^{\star, 1}$ \\ 1 Department of Biological Sciences, Columbia University, 530 120th Street, \\ New York, NY 10027, USA \\ * Corresponding author: C Prives, Department of Biological Sciences, Columbia \\ University, 530 120th Street, New York, NY 10027, USA. \\ Tel: + 212854 2557; Fax: + 212865 8246; E-mail: clp3@ Columbia.edu
}

Received 17.1.06; revised 28.2.06; accepted 28.2.06; published online 31.3.06 Edited by G Melino

\section{Abstract}

The $\mathrm{p} 53$ tumor suppressor protein is a DNA sequence-specific transcriptional regulator that, in response to various forms of cellular stress, controls the expression of numerous genes involved in cellular outcomes including among others, cell cycle arrest and cell death. Two key features of the p53 protein are required for its transcriptional activities: its ability to recognize and bind specific DNA sequences and to recruit both general and specialized transcriptional co-regulators. In fact, multiple interactions with co-activators and corepressors as well as with the components of the general transcriptional machinery allow p53 to either promote or inhibit transcription of different target genes. This review focuses on some of the salient features of the interactions of p53 with DNA and with factors that regulate transcription. We discuss as well the complexities of the functional domains of p53 with respect to these interactions.

Cell Death and Differentiation (2006) 13, 951-961.

doi:10.1038/sj.cdd.4401916; published online 31 March 2006

Keywords: p53; transcriptional activation/suppression; functional domain; co-activator

Abbreviations: $A Q P 3$, aquaporin 3; ARF, alternate open reading frame; (d)ADP, (deoxy)adenosine diphosphate; (d)ATP, (deoxy)adenosine triphosphate; CARM1, coactivator-associated arginine methyltransferase 1; Cdc2, cell division cycle 2; Chk1, checkpoint kinase 1; CRF, chromatin remodeling factor; CTD, Cterminal basic domain; DBD, DNA-binding core domain; EMSA, electrophoretic mobility shift assay; Ets-1, V-ets erythroblastosis virus E26 oncogene homolog 1 (avian); GADD45, growth arrest and DNA damage inducible gene 45; (d)GTP, (deoxy)guanosine triphosphate; HAT, histone transacetylase; HDAC, histone deacetylase; IGFBP3, insulin-like growth factor binding protein 3; MDM2, mouse double minute 2; MDR1, P-glycoprotein (multidrug resistance 1); $\mathrm{NAD}^{+}$, nicotinamide adenine dinucleotide; NMR, nuclear magnetic resonance; PIG3, p53-induced gene 3; Pin, peptidyl-prolyl cis/trans isomerase; PRMT1, protein arginine methyltransferase 1; RE, p53 DNA consensus recogni- tion element; RNA Pol I/II/III, DNA-dependent RNA Polymerase I or II or III; rRNA, ribosomal RNA; tRNA, transfer RNA; SAGE, serial analysis of gene expression; SnoN, SKI-like; mSin3a, transcriptional regulator SIN3A; TA, N-terminal transactivation domain; TDP, thiamine diphosphate; TFIIA, transcription factor IIA; TFIID, transcription factor IID; TFIIIB, transcription factor IIIB; TXSA, thromboxane synthase; VP16, Herpes simplex virus transactivator VP16; p21/CDKN1, cyclin-dependent kinase inhibitor $1 \mathrm{~A}$; p52, nuclear factor of kappa light polypeptide gene enhancer in B-cells 2, p49/p100; p53, tumor suppressor p53; p300, transcriptional co-activator protein p300

\section{Introduction}

P53 sits at the hub of an extremely complex network within the living cell. Multiple signals, perhaps the most well studied being DNA damage, lead to the functional activation of p53 which can upregulate or downregulate numerous target genes, thus, initiating a series of events resulting in cell-cycle arrest, senescence or apoptosis among other outcomes (reviewed in Vogelstein et al', Prives and $\mathrm{Hall}^{2}$ ).

The complexity of p53 as a protein mirrors the functional complexity of p53-dependent events. Active p53 protein exists in the cell as a tetramer made of four identical subunits. ${ }^{3}$ Each monomer, in turn, consists of several well-defined domains including a multipartite $\mathrm{N}$-terminal transactivation (TA) domain (residues 1-73) a proline-rich region (63-97), the centrally located and highly conserved DNA-binding core domain (DBD) (residues 94-312) and within the C-terminus are located its tetramerization domain (residues 324-355) followed by an unstructured basic domain (CTD) (residues 360-393).

An additional layer to p53 complexity is added by the numerous post-translational modifications this protein may undergo, the most important of which seem to be phosphorylation, acetylation and ubiquitination (reviewed in Brooks and $\mathrm{Gu}^{4}$, Appella and Anderson ${ }^{5}$ ). Site- and time-specific modifications of certain p53 residues are likely to regulate its activity as well as its half-life although contradictory findings in the literature imply great complexity in this regard.

Though recent studies have demonstrated that p53 can also produce apoptosis through non-transcriptional processes that occur in the cytoplasm (reviewed in Erster and Moll ${ }^{6}$ ), in this review we will focus on the roles and regulation of p53 as a transcriptional activator and repressor. From that vantage point $\mathrm{p} 53$ may be viewed as possessing two critical functions and their related modules: DNA-binding and cofactor recruiting. We would then suggest that the other regions of p53 serve to assist these two primary modules in performing their functions.

Since the discovery of the first transcription targets of $\mathrm{p} 53$ in the early 1990s ( $p 21, G A D D 45$, cyclin G, bax and others, 
reviewed in Ko and Prives $^{7}$ ) the list of genes whose expression depends on p53 has grown dramatically and continues to expand. Such p53 targets have been identified either as single genes or using different screening techniques such as DNA microarrays or SAGE technology. In the current review we will focus mainly on a number of aspects of the p53 protein's function as a transcription factor and its ability to modulate the transcription of downstream genes in a positive and negative manner. We will also discuss some cis- and trans-elements participating in these processes. P53 is one of the most extensively scrutinized mammalian regulatory genes to have been examined in recent decades. Given the confines of the format of this review, it has been therefore impossible to cite all of the excellent studies that have focused on its roles as a transcription factor. We sincerely apologize in advance to those whose work we have unintentionally omitted in this article.

\section{p53 Binding to DNA}

\section{The p53 DNA consensus recognition element (RE)}

To initiate the chain of events resulting in either inhibition of cell-cycle progression or programmed cell death, p53 must recognize and bind to its recognition elements (REs) that are located in the vicinities of its target genes. In most cases, p53 REs are found within a few thousand base pairs of transcriptional start site and frequently p53 target genes have at least two widely spaced p53 REs. The consensus p53 DNA $\mathrm{RE}$ consists of two pairs (half-sites) of head-to-head arranged pentamers, 5'-PuPuPuCA/TA/TGPyPyPy-3' (Pu is purine, $\mathrm{Py}$ is pyrimidine) separated by $0-13$ nucleotides. ${ }^{8}$ The sequence within the pentamers as well as the pentamers mutual orientation is the important determinant that may influence both, p53 binding ability and activity. ${ }^{9,10}$ Strong p53 REs have been shown to possess certain general features. The most important of them are (i) the presence of highly conserved and obligate $\mathrm{C}$ and $\mathrm{G}$ residues (ii) either 0 or $1 \mathrm{bp}$ spacing between the two half-sites, and (iii) no more than 3 non-consensus bases within RE. ${ }^{11,12}$ Interestingly, the presence of AT residues in the middle of each half-site results in the strongest positive activation, whereas non-consensus bases are associated with low functionality noticeably affecting p53dependent transactivation. ${ }^{12}$

p53 may also recognize REs whose structure is somewhat different from the consensus RE. For instance, one that is weakly induced by $p 53$ is AQP3, in which, the RE is made up of three pairs of pentamers. ${ }^{13}$ Another example is the p53 RE located within the promoter of the MDR1 gene (see below). ${ }^{14}$ $A$ third is the microsatellite region within the PIG3 gene that was shown to function even more effectively as a p53 RE than a more canonical binding site within the same promoter. ${ }^{15}$ Finally, Walter et al. ${ }^{16}$ have recently demonstrated the ability of p53 to recognize and bind to CTG. CAG trinucleotide repeats with the subsequent induction of topological alterations in DNA.

It is noteworthy that among p53-regulated genes their respective levels of activation or inhibition of transcription vary broadly. This is due, at least in part, to the variation within the individual p53 REs. When tested in a yeast model system such variations resulted in up to 1000-fold difference in transactivation. ${ }^{10,17}$

Yeast-based assays also have been used by recent studies to identify new potential p53 REs and to evaluate the impact of genetic variation within the REs on p53-dependent transactivation. ${ }^{11}$ In addition to the discovery of a number of new p53 potential targets, they established a link between particular p53 RE alleles and their influences on p53 transactivation.

It should be noted, however, that such differences observed in yeast systems may not be replicated in mammalian cells.

\section{P53 has two autonomous DNA-binding domains}

The p53 core domain

The large central core DBD demonstrates high affinity toward the consensus RE (see above), whereas the small, Cterminally located highly basic domain (CTD) has been shown to bind to DNA without sequence specificity (reviewed in Jayaraman and Prives ${ }^{18}$, Kim and Deppet ${ }^{19}$, Liu and KuleszMartin $^{20}$ ). On the basis of crystallographic data a model has been suggested in which each pentamer of the RE interacts with the DBDs comprising a p53 tetramer. ${ }^{21}$ The crystal structure of the p53 core DBD revealed that its complex $\beta$-sheet sandwich and loop-sheet-helix motif are the sequence-specific DNA-binding determinants of the core. This model has been validated in a number of NMR-based and biochemical studies. ${ }^{22-24}$

Among more than 18000 currently known mutations in p53 that result in either partial or complete loss of its wild-type (wt) functions, amino acids within the p53 DBD are by far the most frequent mutational targets. ${ }^{25}$ The mutations situated in the DBD can disrupt p53-specific DNA binding by several possible ways. Mutations at some positions (e.g. R273) decrease the binding ability of p53 by simply eliminating direct contacts between the protein and DNA, ${ }^{21,26}$ while some other mutations (e.g. R175, G245, R249, R282) diminish binding by destabilizing the tertiary structure of p53 DBD. ${ }^{27,28}$ Mutation at position 248 (R248), in addition to breaking DNA-protein contacts, also introduces extensive structural changes into the DBD. ${ }^{27}$ Among these mutations are also those that lead to the loss or significant decrease in $\mathrm{Zn}^{2+}$ ions, normally chelated by $\mathrm{C} 176$ and $\mathrm{H} 179$ of the L2 loop and by $\mathrm{C} 238$ and C242 of the L3 loop. ${ }^{21}$ In fact, $\mathrm{Zn}^{2+}$ release from the wild-type DBD of p53 leads to a conformational change of L2 and L3 loops and facilitates conversion of an active soluble protein into one that is insoluble and inactive. ${ }^{29}$ Importantly, the loss of $\mathrm{Zn}^{2+}$ ions is facilitated by elevating temperature, a finding which may provide an explanation of the unusual lossof-function phenomenon demonstrated by $\mathrm{p} 53$ at $37^{\circ} \mathrm{C}^{30}$ although the $\mathrm{N}$-terminus has also been shown to be involved in stabilization of temperature-sensitive DNA binding by wildtype $^{31}$ and mutant ${ }^{32}$ forms of p53.

Additionally, Butler and Loh $^{33}$ have described the ability of some DBD mutants (G245S, R249S, R282Q) to facilitate the loss of p53 function by causing DBD to cycle unusually rapidly between folded and unfolded states. During such cycling a fraction of DBD caught in a functionally inactive state continually increases. 
Recognition and making contact with the different bases within a consensus $R E$ requires a significant level of flexibility of the p53 DBD within a tetramer. The same flexibility, though, seems to be responsible for the ability of some p53 mutants to bind and inactivate the other two p53 relatives, p63 and $\mathrm{p} 73,{ }^{34-37}$ as well as to force wild-type p53 molecules (translated from the remaining wild-type p53 allele) into a mutant conformation.

Surprisingly, while the existence of even one mutated p53 allele in the cell results in a gain-of-function phenotype, ${ }^{38,39}$ Chan et al. ${ }^{40}$ found that at least three DNA-binding defective molecules of p53 are needed in order to effectively inactivate the tetramer. They reported that in their experiments the presence of one or two mutated DBD molecules within a tetramer does not significantly reduce p53 transcriptional activation. Speculatively, the existence of partially active tetramers in the cell may lead to a new phenotype via appearance of an unusual binding surface on a p53 molecule, which may change the pattern of coactivators/corepressors interacting with p53 or even promote new contacts. Alternatively, mutations in the DBD may either result in the ability of p53 to bind selectively to target genes or (more speculatively) to some novel DNA sequences thus altering the normal global transcriptional response to $\mathrm{p} 53$.

\section{The p53 C-terminal DNA-binding domain}

The small CTD of p53 initially attracted attention because of its ability to bind to nonspecific sequences in DNA, and also its potential ability to directly regulate binding by the p53 sequence-specific DBD. Unstructured and rich in both serine and lysine residues, the CTD can be subjected to several types of modification the most well studied being phosphorylation and acetylation. ${ }^{5,41,42}$. In addition, it has been suggested that C-terminal lysines of p53 may be involved in the regulation of stability of p53, as they are subjected to MDM2-mediated ubiquitination. In fact, the same lysine residues are acetylated by histone acetyl transferases (HATs) which result in p53 stabilization and activation. ${ }^{43-45}$ Finally, there are data that neddylation, ${ }^{44}$ methylation, ${ }^{46}$ and sumoylation (reviewed in Muller et al. ${ }^{47}$ ) of the CTD can regulate p53 functions.

What is the meaning of such C-terminal modifications? It was originally observed that, using the electrophoretic mobility shift assay (EMSA), either binding by the C-terminal antibody PAb 421 or phosphorylation of the penultimate residue, S392 leads to increased ability of p53 to bind to DNA. It was hypothesized that after DNA damage, the CTD of p53 becomes modified by phosphorylation leading to increased binding to its transcriptional target genes (Reviewed in Ahn and Prives ${ }^{48}$ ). This suggestion was extended to a proposal that upon such modification p53 normally in a latent state in cells undergoes a modification-induced allosteric conformational shift that somehow positively affects the ability of the core domain to bind to DNA. In fact, in vitro and in vivo obtained data suggested that not only phosphorylation but CTD acetylation also enhances the sequence-specific DNA binding of p53. ${ }^{49-51}$ This concept was also supported by the observation that deletion of the $\mathrm{C}$-terminus increases its ability to bind to DNA using similar experimental conditions. The allosteric model was subsequently challenged by Anderson et al. who showed that the interactions of $\mathrm{p} 53$ with PAb 421 or long DNA molecules had respectively stimulatory or inhibitory effects on its ability to bind to a short RE-containing oligonucleotide. $^{52}$ They proposed that the C-terminus binding to long DNA interferes with the ability of the core to bind to DNA and that modification of the C-terminus prevents such interference by blocking its ability to bind to nonspecific DNA. Their hypothesis was supported by NMR analysis that showed that both full length and C-terminally deleted versions of p53 have essentially similar structures ${ }^{53}$ and by experiments from the group of Fersht showing that when fully acetylated the C-terminus completely loses DNA binding capacity. ${ }^{54}$ Relevantly, Espinosa and Emerson reported that although acetylation appears to increase the p53-binding affinity toward short double-stranded DNA fragments it does not affect ability of p53 to bind to its specific RE in the context of chromatin or longer DNA molecules. ${ }^{55}$ It has become clear that evaluating the p53 DNA binding using short double-strand oligonucleotides does not provide a complete picture. Importantly as well, quantitative chromatin immunoprecipitation analysis has failed to demonstrate allosteric regulation of DNA binding of p53: neither of the two groups of p53 target genes - with relatively high promoter occupancy in vivo or with much weaker DNA binding exhibit significant enrichment in p53 binding after genotoxic stress. ${ }^{56}$ Finally, it was recently shown that substitution of all p53 CTD lysines for arginines does not significantly affect the activities or stability of p53 in a mouse model. ${ }^{57,58}$

Though controversial, the importance of the CTD in p53 functioning has been continuing to reveal itself in a number of more recent publications. McKinney and Prives, ${ }^{59}$ Fojta et al., ${ }^{60}$ and Palecek et al. ${ }^{61}$ have shown that the CTD is important for binding to various non-linear DNAs. In another study, McKinney et al. ${ }^{62}$ have demonstrated the involvement of CTD in the ability of p53 to diffuse linearly on DNA. Both, McKinney et al. ${ }^{62}$ and Liu et al. ${ }^{63}$ showed as well that the CTD is required for efficient promoter activation in vivo by $\mathrm{p} 53$. Moreover, Harms and Chen ${ }^{64}$ have recently reported that the CTD inhibits p53-dependent induction of IGFBP3 gene. In this case it is HAT-related inhibitory activity, but not p53 DNA binding ability, that is bound to CTD.

The ability of p53 to interact with DNA sequences can be modulated by the presence of small molecules. First, as has been demonstrated, elevating concentrations of transition metals such as $\mathrm{Zn}^{2+}, \mathrm{Ni}^{2+}$, and $\mathrm{Co}^{2+}$ inhibit $\mathrm{p} 53$ binding to the DNA RE. ${ }^{65}$ Of these three, $\mathrm{Zn}^{2+}$ ions have had the most devastating effect when added in the concentration 5-20 $\mu \mathrm{M}$. Second, the presence of ADP or dADP has been found to stabilize p53-DNA complexes, while addition of ATP dATP, GTP or dGTP apparently can facilitate the release of $p 53$ from such complexes. ${ }^{66}$

Two other molecules, thiamine diphosphate (TDP) and nicotinamide adenine dinucleotide $\left(\mathrm{NAD}^{+}\right)$have been recently shown to bind to $\mathrm{p53}$, induce conformational changes, and inhibit DNA binding. ${ }^{67}$ The authors propose that the level and rate of $\mathrm{NAD}^{+}$synthesis may directly modify p53 DNA specificity. In addition to small molecules, other factors, like the supercoiled nature of the DNA or local DNA bending, may facilitate p53-DNA interactions. ${ }^{59,61}$ Importantly, it has been 
demonstrated earlier that there is a direct correlation between the stability of p53-DNA complexes and the ability of the DNA to be bent by the p53 DBD upon binding. ${ }^{68}$ A summary of the above regulatory effectors is shown in Figure 1. For the purpose of simplicity and clarity we have omitted from Figure 1 the numerous post-translational modifications and protein factors previously reported to regulate p53 DNA binding. Furthermore, as discussed above some of these modifications (e.g. acetylation) and proteins have been shown to either stimulate or inhibit p53 DNA binding depending on the experimental context.

\section{The Complexity of the p53 Transactivation Domain}

The first suggestion that p53 functions as a transcriptional regulator came from that observation that its $\mathrm{N}$-terminus (TA) when fused to a heterologous DNA-binding domain can serve as an activation domain in yeast. Owing to the relatively high number of paired aspartate and glutamate residues located within it, this domain belongs to the class of 'acidic' activation domains that are known to interact with a number of proteins that populate the general transcription machinery (reviewed in Ko and Prives ${ }^{7}$ ). Although the conclusions based on these observations that $\mathrm{p} 53$ is a transcriptional activator turned out to be correct, formal proof that p53 is a sequence-specific transcriptional activator was only obtained when full-length p53 was studied in that context.

The TA domain is one of the several unstructured regions within p53. ${ }^{69}$ Though the entire $\mathrm{N}$-terminal region of p53 is natively unfolded, and that seems to be its functional state, ${ }^{70}$ NMR-based studies have found several small 'islands' of secondary structure within the TA: the helix formed by residues Thr18-Leu26, and the two turns are shaped by residues Met40-Met44 and Asp48-Trp53, respectively. ${ }^{71}$ It has been suggested that these regions may represent recognition scaffolds for p53-interacting proteins. Interestingly, as is the case with other activation domains, single-point mutations within the TA domain do not demonstrate such a devastating effect as in the case of DBD. ${ }^{72}$ Thus, the overall shape of the TA polypeptide chain may not be affected by single amino-acid changes and would seem to be more important for recognition and protein interaction rather than any specific residues. Nevertheless, simultaneous mutation of two hydrophobic residues Leu22 and Trp23 markedly impairs (but does not abolish) transactivation by p53. ${ }^{72}$ Interestingly, mutation of residues Trp53 and Phe54 appears to affect specifically the ability of p53 to regulate some of its proapoptotic target genes in some settings. ${ }^{73}$

Though the results obtained by mutational analysis of p53 TA have demonstrated the presence of two highly important subdomains within it and set its boundaries between the residues $1-42$ and $43-73,{ }^{74}$ several other regions of TA (as well as amino acids located within them) have been shown to participate in the process of transcriptional regulation. For example, some co-activators have been shown to interact with p53 within residues $63-97 .{ }^{75}$ Residues $63-97$ span a proline-rich region shown to be important for the Pin-induced modification of the TA structure, ${ }^{76,77}$ and to interact directly with $\mathrm{p} 300 .{ }^{78}$ One more functionally divergent region within the $\mathrm{N}$-terminal part of p53 is a recently identified repression domain. ${ }^{79}$ As defined by mutation analysis, it is located between proline-rich domain and DNA-core domain (residues 100-116). Importantly, this domain can function as an independent heterologous repressor, and has been shown to decrease VP16-driven activation up to 20 times in human embryonal carcinoma cells, when being fused to VP16 transactivator. $^{79}$ As wild-type p53 is found to be overexpressed in some type of tumors, it has been proposed that the newly identified domain may play an important role in repression of the basal activity of $p 53$. Factors that are or can be specifically recruited by this domain, and that might be essential for the repression phenomenon found, are not known at present. Thus, these and other experiments further highlight the likelihood that transcriptional regulation by $\mathrm{p} 53$ involves several different regions within its $\mathrm{N}$-terminus.

In addition to the multipartite nature of the activation domain of p53, there are three other reasons why this is an exceeding complex region. First, it is the region to which its negative regulator Mdm2 binds and targets p53 for both repression of its transcriptional regulation functions and also for proteasome-mediated degradation (reviewed in Bond et al. ${ }^{80}$ ). Second, it was reported to possess a previously unknown nuclear export signal spanning the residues $11-27 .{ }^{81}$ Finally,

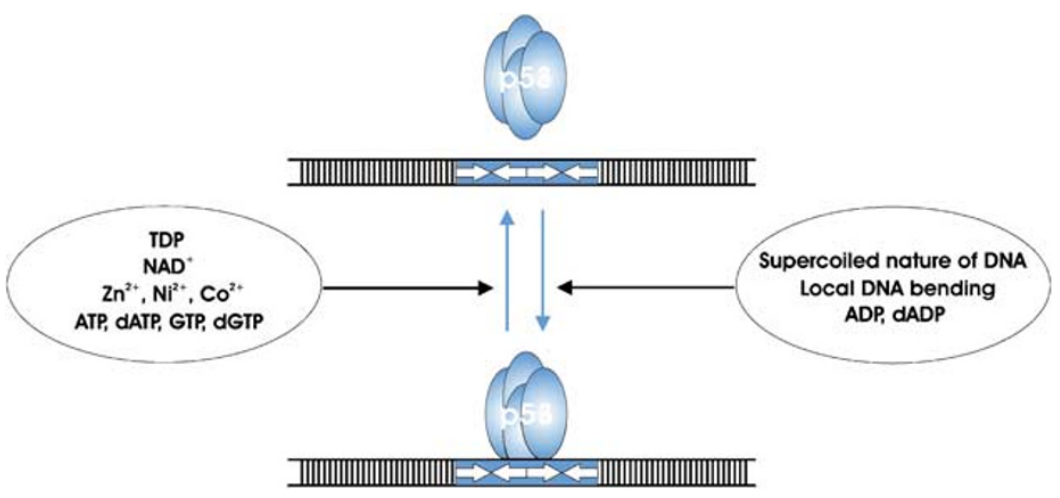

Figure 1 Factors known to have an effect on p53-DNA interaction. p53 tetramer is schematically shown as four blue ovals. DNA is shown as linear fragment with four white arrows within representing p53 RE made of four head-to-head arranged pentamers 
the N-terminus of p53 is extensively modified. Site-specific phosphorylation of the TA domain is important for both, p53 stability $^{82,83}$ and activity ${ }^{50,84-87}$ and has been shown to be interdependent. ${ }^{88}$ There are also qualitative differences in phosphorylation in response to different genotoxic agents. For example, phosphorylation of Thr18 has been shown to be stronger when cells are exposed to ionizing radiation and adriamycin rather than to UV light while phosphorylation at Ser33, Ser37, and Ser46 has been more pronounced in case of UV treatment. ${ }^{88}$

As in the case with p53 CTD modifications, the role of sitespecific phosphorylation of the key serines within TA domain has been challenged by earlier ${ }^{89}$ and some more recent data. Thompson et al. ${ }^{90}$ using Nutlin-3, a recently developed small molecule MDM2 antagonist, have not detected any induction in the phosphorylation of p53 and yet both its DNA sequencespecific binding and ability to transactivate its target genes were unaltered when compared to p53 that is induced after forms of DNA damage that lead to extensive $\mathrm{N}$-terminal modifications.

\section{Transcription Regulation by p53}

Several views exist on the mechanism by which p53 may promote transcription. The first one is built on the assumption that the promoter region of the gene to be activated by p53 is usually not accessible to the general transcription factors and RNA polymerase. In this scenario binding of p53 to its REs within a promoter would facilitate promoter opening via recruiting either chromatin remodeling factors (CRF) ${ }^{91,92}$ (though see reference Hill et al. ${ }^{93}$ ) or histone transacetylases $(\text { HAT })^{94-97}$ and/or methyltransferases ${ }^{98}$ (Figure 2). This view has been validated recently in a significant number of studies. Physical and functional interactions between p53 and p300 HAT have been well documented. ${ }^{49,55,94-97}$ The involvement of PRMT1 and CARM1 methyltransferases in p53 function has been also demonstrated in the in vitro study utilizing a chromatin template with GADD45 p53 RE. ${ }^{98}$ Thus, histone modifications and the subsequent alterations in chromatin structure and function seem to be one of the major outcomes of p53 binding to the RE.

a

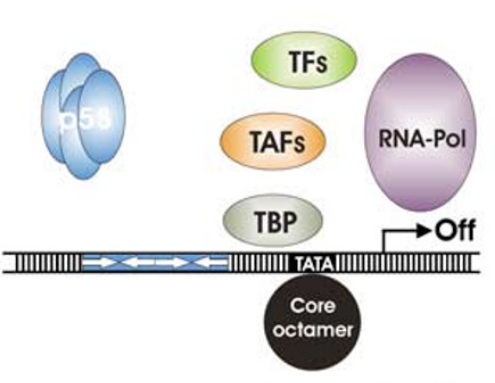

Promoter in closed conformation

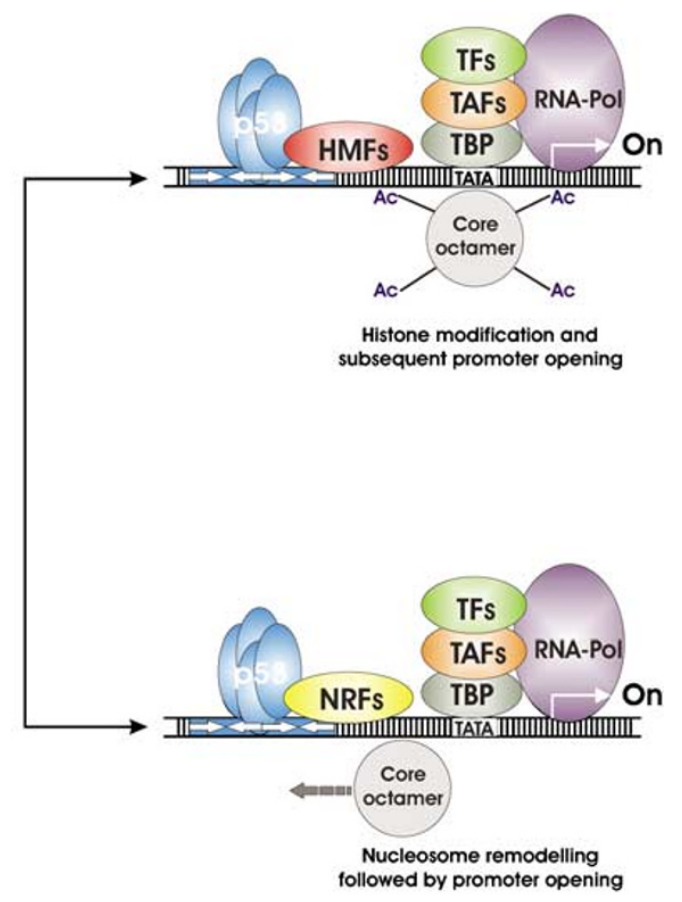

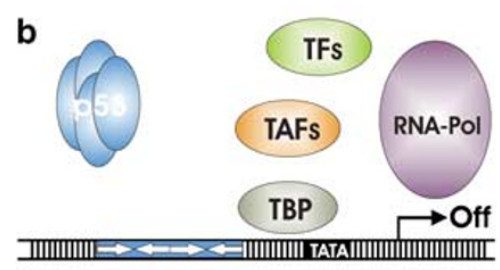

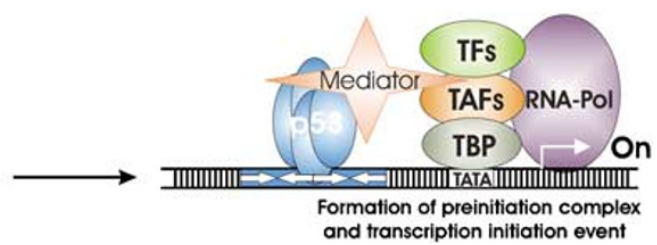

Figure 2 Different modes of p53-dependent transcriptional activation. Abbreviations : Ac, acetate; TATA, TATA box; TBP, TATA-binding protein; TAFs, transcriptionassociated factors; TFs, other transcription factors; RNA-Pol, RNA Polymerase; HMFs, histone modifying factors; NRFs, nucleosome remodelling factors. p53 consensus RE is shown by four white arrows; 'Off' and 'On' stand for transcription switched off or on, respectively. For simplicity, DNA is shown as linear fragment. (a) Transcriptional activation via recruiting HMFs (for example, HAT p300) (upper panel) or NRFs (for example, SWI/SNF complex) (lower panel). (b) Transcriptional activation via interaction with the components of mediator complex and subsequent formation of preinitiation complex 
In addition, p53 has been shown to facilitate formation of preinitiation complex via direct interactions with the components of Mediator complex. ${ }^{99,100}$ p53 can also stimulate transcription by enhancing the recruitment of the basal transcription factors, such as TFIIA and TFIID through the direct interactions with them, and by inducing conformational change(s) in these complexes. ${ }^{7,101}$

Another view of p53-depending transcriptional activation is based on the observation that the regions of chromatin within the vicinity of several p53 responsive promotes (including GADD45 and MDM2) exist in open conformations regardless of the conditions (normal versus genotoxic). ${ }^{102-104}$ Constitutive hypersensitivity of these promoters to DNase I led to the suggestion that they might be nucleosome-free, and do not require significant chromatin alterations to become activated. By analogy with some genes, which are regulated by promoter proximal pausing and factors facilitating reinitiation of stalled RNA Polymerase, p53 has been suggested to induce reinitiation of transcription. ${ }^{104}$ For further evaluation this model clearly requires more data.

The subject of p53-dependent transcription activation, including an up-to-date list of positively regulated genes, has been more than adequately covered in a series of recent reviews. ${ }^{105,106}$

\section{Negative regulation of transcription by $\mathrm{p} 53$}

Although well established as a transcriptional activator, p53 has also been shown to suppress the transcription of certain genes. Indeed, in addition to identification of multiple targets that are activated by $p 53$, expression arrays have indicated that significant numbers of genes are downregulated after induction of p53 in many cases. ${ }^{107-110}$ The molecular background of negative regulation of gene expression by p53 seems to be more diverse. Interestingly, earlier reports have suggested that transcriptional repression by p53 is the key activity that is required for its ability to induce cell death. ${ }^{7}$

p53 can efficiently inhibit transcription driven by all three mammalian RNA polymerases (Pol I, Pol II and Pol III). With respect to $\mathrm{Pol} I \mathrm{I}$ inhibition, several mechanisms have been documented (Figure 3 ). These include repression of transcription activators by physical interaction with and preventing them from activating the promoter ${ }^{111-116}$ or by displacing them from the adjusting or overlapping binding sites within the promoter, ${ }^{117-120}$ interference with the assembly of transcription machinery, ${ }^{7,121}$ repression through the recruitment of histone deacetylase (HDAC) and, possibly, other chromatin modifying factors, ${ }^{122-124}$ and finally through novel REs with the unique architecture that dictates the outcome of p53 binding. ${ }^{14,125}$ Combination of two of the above mechanisms has been also documented. ${ }^{126}$ It should be noted, that the p53-dependent transcriptional repression that depends on HDAC recruitment, has perhaps the most complicated scenario, and in many cases it is mediated by the presence of additional protein(s). The known mediators include mSin3a, ${ }^{122,127}$ SnoN $^{128}$ and p52. ${ }^{129}$

In certain cases p53-induced repression seems to depend on the activation of p53-dependent targets. p53 mediated repression of Chk1, ${ }^{130}$ or Cdc2, Cyclin A2, survivin and some other genes may occur indirectly through the transcriptional activation of p21. ${ }^{131}$ In such cases p21 alone is sufficient to inhibit the transcription to the same extent as p53.

Whatever the nature of p53-dependent repression, it is clear that it requires functionally active p53 protein. Surprisingly, mutations in almost all domains of p53 - TA, DBD, proline-rich and CTD - may abrogate its inhibitory ability, suggesting the specific role for each of the domains during inhibition. For example, p53 TAdeficient mutants lose the ability to repress the transcription of the Map4 gene, ${ }^{132}$ whereas a p53 mutant lacking the proline-rich domain cannot repress a series of promoters as efficiently as wild-type p53. ${ }^{133}$ This domain is also important for p53-Sin3a-mediated transcription inhibition. ${ }^{75,122}$ The Cterminal domain of p53 is required for the interaction between p53 and Ets-1 protein, which is necessary for TXSA repression. ${ }^{112}$

It is intriguing that the presence of a functionally active DBD is required for the inhibition to occur even if binding of p53 to the RE is not necessary. In this context it should be noted that promoters of some downregulated genes have one or more potential p53 REs, not participating in p53-mediated regulation. ${ }^{12,134,135}$ The human small nuclear RNA U1 gene has been shown to contain a high-affinity $R E$ within its promoter which nevertheless seems to be dispensable for p53mediated repression of $\mathrm{U} 1 .{ }^{135}$ Whether recognition of such 'latent' REs depends on the intracellular conditions and/or external stimuli, remains to be found.

Recently, transcriptional repression that results from the binding of p53 to a novel type of 'repression site' RE has been described in the MDR1 promoter. ${ }^{14,125}$ Interestingly, it is orientation of pentamers - 'head-to-tail', instead of 'head-tohead' - within the RE that dictates the type of p53 activity on this promoter. The change of the orientation back to 'normal' results in the significant activation of MDR1. The same authors propose that the inhibition of several other genes, namely, cyclin A, cyclin B1, and ARF, may be driven by the same mechanism, as identical head-to-tail REs have been identified within their promoters. ${ }^{14}$ For cyclin B1, this might be an alternative mechanism, as its repression has been shown to depend on p21/CDKN1. ${ }^{131}$ Surprisingly, two p53 homologues, p63 and p73, do not recognize the Mdr1 repression site RE and are unable to inhibit transcription at MDR1 promoter, suggesting some unique properties for DBD domain of each type. ${ }^{125}$

Taking into account that activity of p53-repressed genes usually correlates with cell proliferation or malignant progression, it is not surprising that p53 may also suppress such activities in a more general way by targeting the components of protein biosynthesis machinery. p53 does it by inhibiting the expression of RNA Pol I ${ }^{136,137}$ and RNA Pol III 135,138,139 transcribed genes. Pol I-driven transcription is repressed by p53 interference with the assembly of a productive initiation complex on the rRNA promoter, ${ }^{136,137}$ whereas transcription of tRNAs seems to be downregulated directly, through the interaction with the components of Pol III transcription machinery, ${ }^{138,139}$ and indirectly, by $\mathrm{p} 53$-dependent degradation of TFIIIB. ${ }^{140}$ Both, rRNA and tRNA synthesis is significantly elevated in fibroblasts from p53-knockout mice. ${ }^{137,141}$ 
a
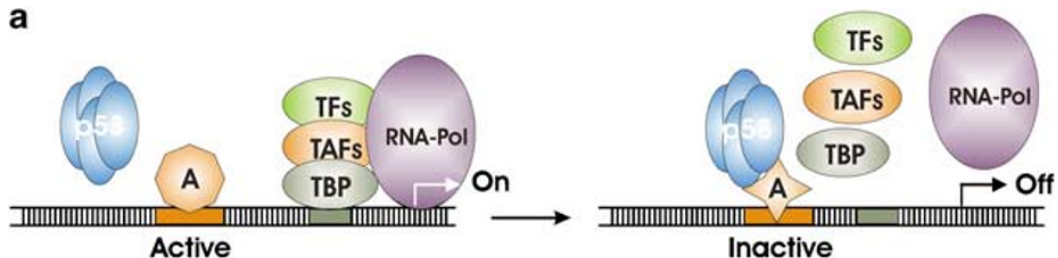

Inactive

b

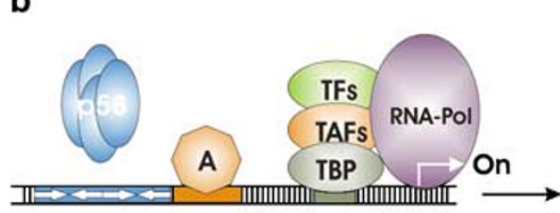

Active

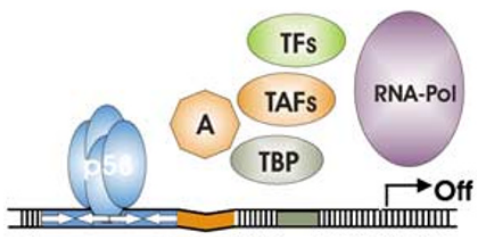

Inactive

C
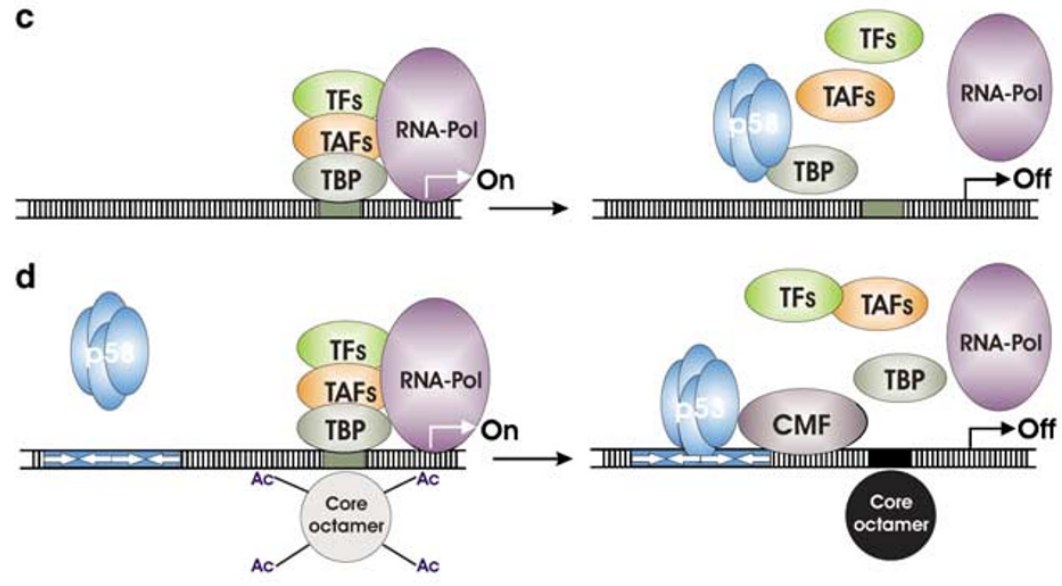

e

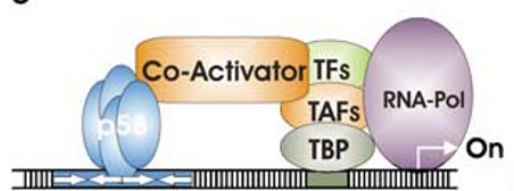

But

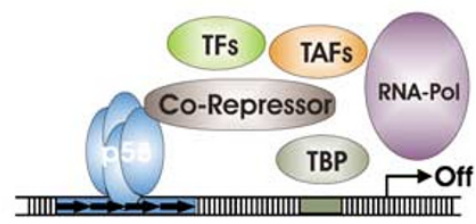

Figure 3 Different modes of p53-dependent transcriptional repression. Abbreviations: A, site-specific transcriptional activator; CMF, chromatin-modifying factor; the other abbreviations are as in Figure 2. (a) p53 inhibits transcription by physical interaction and inactivation of the specific activator or (b) by displacing it from the adjusting or overlapping binding sites within the promoter. (c) Transcriptional repression by affecting the assembly of transcription machinery though the direct interaction with basal transcription factor(s). (d) Transcriptional repression via recruiting CMF(s) (for example, HDAC) followed by subsequent modification of core histones and promoter closing. (e) Transcriptional repression through novel REs (represented by four black arrows) with the unique architecture that dictates the outcome of p53 binding

\section{Concluding Remarks}

The ability of p53 to regulate transcription of a number of genes in response to different genotoxic signals lies at the center of its function as a major tumor suppressor. The ongoing process of identification of numerous p53-regulated genes has been slowly revealing the multifaceted and somewhat knotted mechanism by which p53 exerts its functions in cells. p53 clearly demonstrates the interdependence of the many 'discrete' steps in the process of transcription regulation, and their importance for the final outcome. Yet, despite the myriad of studies delving into the mechanisms by which p53 regulates its targets there is still much more to learn about this fascinating protein. Looking ahead into the future we envisage many new avenues to be explored, some of which will require novel or more refined technologies. The contacts made by p53 with components of the transcriptional machinery need to be determined at the atomic level. We would also hope to gain a dynamic or kinetic view of p53 as it regulates transcriptional target genes. How will p53 be affected by the other p53 isoforms recently identified $^{142,143}$ or by the presence of isoforms encoded by its sibling genes, p63 and p73 (reviewed in Harms and Chen ${ }^{144}$ )? Finally, the 'Holy Grail' of p53 research still lies ahead: capitalizing upon past and future basic research discoveries to improve diagnosis and treatment of cancer patients.

\section{References}

1. Vogelstein B, Lane D and Levine AJ (2000) Surfing the p53 network. Nature 408: $307-310$. 
2. Prives $C$ and Hall PA (1999) The p53 pathway. J. Pathol. 187: 112-126.

3. Jeffrey PD, Gorina $S$ and Pavletich NP (1995) Crystal structure of the tetramerization domain of the p53 tumor suppressor at 1.7 angstroms. Science 267: 1498-1502.

4. Brooks CL and Gu W (2003) Ubiquitination, phosphorylation and acetylation: the molecular basis for p53 regulation. Curr. Opin. Cell Biol. 15: 164-171.

5. Appella E and Anderson CW (2001) Post-translational modifications and activation of p53 by genotoxic stresses. Eur. J. Biochem. 268: 2764-2772.

6. Erster S and Moll UM (2005) Stress-induced p53 runs a transcriptionindependent death program. Biochem. Biophys. Res. Commun. 331 843-850.

7. Ko LJ and Prives C (1996) p53: puzzle and paradigm. Genes Dev. 10: 1054-1072.

8. Hoh J, Jin S, Parrado T, Edington J, Levine AJ and Ott J (2002) The p53MH algorithm and its application in detecting p53-responsive genes. Proc. Natl. Acad. Sci. USA 99: 8467-8472.

9. Zhao R, Gish K, Murphy M, Yin Y, Notterman D, Hoffman WH, Tom E, Mack $\mathrm{DH}$ and Levine $\mathrm{AJ}$ (2000) Analysis of p53-regulated gene expression patterns using oligonucleotide arrays. Genes Dev. 14: 981-993.

10. Inga A, Storici F, Darden TA and Resnick MA (2002) Differential transactivation by the p53 transcription factor is highly dependent on p53 level and promoter target sequence. Mol. Cell. Biol. 22: 8612-8625.

11. Tomso DJ, Inga A, Menendez D, Pittman GS, Campbell MR, Storici F, Bell DA and Resnick MA (2005) Functionally distinct polymorphic sequences in the human genome that are targets for p53 transactivation. Proc. Natl. Acad. Sci. USA 102: 6431-6436.

12. Resnick MA, Tomso D, Inga A, Menendez D and Bell D (2005) Functional diversity in the gene network controlled by the master regulator p53 in humans. Cell Cycle 4: 1026-1029.

13. Zheng $X$ and Chen $X$ (2001) Aquaporin 3, a glycerol and water transporter, is regulated by $p 73$ of the $p 53$ family. FEBS Lett. 489: 4-7.

14. Johnson RA, Ince TA and Scotto KW (2001) Transcriptional repression by 553 through direct binding to a novel DNA element. J. Biol. Chem. 276: 27716-27720.

15. Contente A, Dittmer A, Koch MC, Roth J and Dobbelstein M (2002) A polymorphic microsatellite that mediates induction of PIG3 by p53. Nature Genet. 30: 315-320.

16. Walter K, Warnecke G, Bowater R, Deppert W and Kim EL (2005) tumor suppressor p53 binds with high affinity to CTG. CAG trinucleotide repeats and induces topological alterations in mismatched duplexes. J. Biol. Chem. 280: 42497-42507.

17. Resnick MA and Inga A (2003) Functional mutants of the sequence-specific transcription factor p53 and implications for master genes of diversity. Proc Natl. Acad. Sci. USA 100: 9934-9939.

18. Jayaraman $L$ and Prives $C$ (1999) Covalent and noncovalent modifiers of the p53 protein. Cell Mol. Life Sci. 55: 76-87.

19. Kim $E$ and Deppert $W(2006)$ The versatile interactions of $p 53$ with DNA: when flexibility serves specificity. Cell Death Differ. 13: 885-889.

20. Liu $Y$ and Kulesz-Martin MF (2006) Sliding into home: facilitated p53 search for targets by the basic DNA binding domain. Cell Death Differ. 13 881-884.

21. Cho Y, Gorina S, Jeffrey PD and Pavletich NP (1994) Crystal structure of a p53 tumor suppressor-DNA complex: understanding tumorigenic mutations. Science 265: 346-355.

22. Klein C, Planker E, Diercks T, Kessler H, Kunkele KP, Lang K, Hansen S and Schwaiger M (2001) NMR spectroscopy reveals the solution dimerization interface of p53 core domains bound to their consensus DNA. J. Biol. Chem. 276: 49020-49027.

23. Rippin TM, Freund SM, Veprintsev DB and Fersht AR (2002) Recognition of DNA by 053 core domain and location of intermolecular contacts of cooperative binding. J. Mol. Biol. 319: 351-358.

24. McLure KG and Lee PW (1998) How p53 binds DNA as a tetramer. EMBO J. 17: $3342-3350$

25. Data available at International Agency for Research on Cancer TP53, database R8, available at www.iarc.fr/p53.

26. Bullock AN, Henckel J, DeDecker BS, Johnson CM, Nikolova PV, Proctor MR Lane DP and Fersht AR (1997) Thermodynamic stability of wild-type and mutant p53 core domain. Proc. Natl. Acad. Sci. USA 94: 14338-14342.
27. Wong KB, DeDecker BS, Freund SM, Proctor MR, Bycroft M and Fersht AR (1999) Hot-spot mutants of p53 core domain evince characteristic loca structural changes. Proc. Natl. Acad. Sci. USA 96: 8438-8442.

28. Bullock AN, Henckel J and Fersht AR (2000) Quantitative analysis of residual folding and DNA binding in mutant p53 core domain: definition of mutant states for rescue in cancer therapy. Oncogene 19: 1245-1256.

29. Butler JS and Loh SN (2003) Structure, function, and aggregation of the zinc-free form of the p53 DNA binding domain. Biochemistry 42 2396-2403.

30. Foster BA, Coffey HA, Morin MJ and Rastinejad F (1999) Pharmacological rescue of mutant p53 conformation and function. Science 286: 2507-2510.

31. Hansen S, Hupp TR and Lane DP (1996) Allosteric regulation of the thermostability and DNA binding activity of human $\mathrm{p} 53$ by specific interacting proteins. CRC Cell Transformation Group. J. Biol. Chem. 271: 3917-3924.

32. Friedlander $P$, Legros $Y$, Soussi T and Prives $C$ (1996) Regulation of mutant p53 temperature-sensitive DNA binding. J. Biol. Chem 271: 25468-25478.

33. Butler JS and Loh SN (2005) Kinetic partitioning during folding of the p53 DNA binding domain. J. Mol. Biol. 350: 906-918.

34. Di Como CJ, Gaiddon C and Prives C (1999) p73 function is inhibited by tumor-derived p53 mutants in mammalian cells. Mol. Cell. Biol. 9: 1438-1449.

35. Gaiddon C, Lokshin M, Ahn J, Zhang T and Prives C (2001) A subset of tumor-derived mutant forms of $p 53$ down-regulate p63 and p73 through a direct interaction with the p53 core domain. Mol. Cell. Biol. 21: 1874-1887.

36. Bensaad K, Le Bras M, Unsal K, Strano S, Blandino G, Tominaga O, Rouillard $D$ and Soussi T (2003) Change of conformation of the DNA-binding domain of p53 is the only key element for binding of and interference with p73. J. Biol. Chem. 278: 10546-10555.

37. Marin MC, Jost CA, Brooks LA, Irwin MS, O'Nions J, Tidy JA, James $N$, McGregor JM, Harwood CA, Yulug IG, Vousden KH, Allday MJ, Gusterson B, Ikawa S, Hinds PW, Crook T and Kaelin Jr WG (2000) A common polymorphism acts as an intragenic modifier of mutant p53 behaviour. Nat. Genet. 25: 47-54.

38. Lang GA, Iwakuma T, Suh YA, Liu G, Rao VA, Parant JM, Valentin-Vega YA, Terzian T, Caldwell LC, Strong LC, El-Naggar AK and Lozano G (2004) Gain of function of a p53 hot spot mutation in a mouse model of Li-Fraumeni syndrome. Cell 119: 861-872.

39. Olive KP, Tuveson DA, Ruhe ZC, Yin B, Willis NA, Bronson RT, Crowley D and Jacks $T$ (2004) Mutant p53 gain of function in two mouse models of Li-Fraumeni syndrome. Cell 119: 847-860.

40. Chan WM, Siu WY, Lau A and Poon RY (2004) How many mutant p53 molecules are needed to inactivate a tetramer? Mol. Cell. Biol. 24 3536-3551.

41. Ljungman M, O'Hagan HM and Paulsen MT (2001) Induction of ser15 and lys382 modifications of p53 by blockage of transcription elongation. Oncogene 20: 5964-5971.

42. Ito A, Lai CH, Zhao X, Saito S, Hamilton MH, Appella E and Yao TP (2001) p300/CBP-mediated p53 acetylation is commonly induced by p53-activating agents and inhibited by MDM2. EMBO J. 20: 1331-1340.

43. Rodriguez MS, Desterro JM, Lain S, Lane DP and Hay RT (2000) Multiple Cterminal lysine residues target p53 for ubiquitin-proteasome-mediated degradation. Mol. Cell. Biol. 20: 8458-8467.

44. Xirodimas DP, Saville MK, Bourdon JC, Hay RT and Lane DP (2004) Mdm2mediated NEDD8 conjugation of p53 inhibits its transcriptional activity. Cell 118: 83-97

45. Li M, Luo J, Brooks CL and Gu W (2002) Acetylation of p53 inhibits its ubiquitination by Mdm2. J. Biol. Chem. 277: 50607-50611.

46. Chuikov S, Kurash JK, Wilson JR, Xiao B, Justin N, Ivanov GS, McKinney K, Tempst P, Prives C, Gamblin SJ, Barlev NA and Reinberg D (2004) Regulation of p53 activity through lysine methylation. Nature 432: 353-360.

47. Muller S, Ledl A and Schmidt D (2004) SUMO: a regulator of gene expression and genome integrity. Oncogene 23: 1998-2008.

48. Ahn J and Prives $C$ (2001) The C-terminus of p53: the more you learn the less you know. Nat. Struct. Biol. 8: 730-732.

49. Gu W and Roeder RG (1997) Activation of p53 sequence-specific DNA binding by acetylation of the p53 C-terminal domain. Cell 90: 595-606.

50. Sakaguchi K, Herrera JE, Saito S, Miki T, Bustin M, Vassilev A, Anderson CW and Appella E (1998) DNA damage activates p53 through a phosphorylationacetylation cascade. Genes Dev. 12: 2831-2841. 
51. Luo J, Li M, Tang Y, Laszkowska M, Roeder RG and Gu W (2004) Acetylation of p53 augments its site-specific DNA binding both in vitro and in vivo. Proc Natl. Acad. Sci. USA 101: 2259-2264.

52. Anderson ME, Woelker B, Reed M, Wang P and Tegtmeyer P (1997) Reciprocal interference between the sequence-specific core and nonspecific C-terminal DNA binding domains of $\mathrm{p} 53$ : implications for regulation. Mol. Cell. Biol. 17: 6255-6264.

53. Ayed A, Mulder FA, Yi GS, Lu Y, Kay LE and Arrowsmith CH (2001) Latent and active p53 are identical in conformation. Nat. Struct. Biol. 8: 756-760.

54. Friedler A, Veprintsev DB, Freund SM, von Glos KI and Fersht AR (2005) Modulation of binding of DNA to the $\mathrm{C}$-terminal domain of $\mathrm{p} 53$ by acetylation. Structure (Cambridge) 13: 629-636.

55. Espinosa JM and Emerson BM (2001) Transcriptional regulation by p53 through intrinsic DNA/chromatin binding and site-directed cofactor recruitment. Mol. Cell 8: 57-69.

56. Kaeser MD and lggo RD (2002) Chromatin immunoprecipitation analysis fails to support the latency model for regulation of p53 DNA binding activity in vivo. Proc. Natl. Acad. Sci. USA 99: 95-100.

57. Krummel KA, Lee CJ, Toledo F and Wahl GM (2005) The C-terminal lysines fine-tune P53 stress responses in a mouse model but are not required for stability control or transactivation. Proc. Natl. Acad. Sci. USA 102 10188-10193.

58. Feng $L$, Lin $T$, Uranishi $H$, Gu W and $X u Y$ (2005) Functional analysis of the roles of posttranslational modifications at the p53 $\mathrm{C}$ terminus in regulating p53 stability and activity. Mol. Cell Biol. 25: 5389-5395.

59. McKinney $\mathrm{K}$ and Prives $\mathrm{C}$ (2002) Efficient specific DNA binding by p53 requires both its central and $\mathrm{C}$-terminal domains as revealed by studies with high-mobility group 1 protein. Mol. Cell. Biol. 22: 6797-6808.

60. Fojta M, Pivonkova H, Brazdova M, Nemcova K, Palecek J and Vojtesek B (2004) Investigations of the supercoil-selective DNA binding of wild type p53 suggest a novel mechanism for controlling p53 function. Eur. J. Biochem. 271: 3865-3876.

61. Palecek E, Brazda V, Jagelska E, Pecinka $P$, Karlovska $L$ and Brazdova $M$ (2004) Enhancement of p53 sequence-specific binding by DNA supercoiling. Oncogene 23: 2119-2127.

62. McKinney K, Mattia M, Gottifredi V and Prives C (2004) p53 linear diffusion along DNA requires its $C$ terminus. Mol. Cell 16: 413-424.

63. Liu Y, Lagowski JP, Vanderbeek GE and Kulesz-Martin MF (2004) Facilitated search for specific genomic targets by p53 C-terminal basic DNA binding domain. Cancer Biol. Ther. 3: 1102-1108.

64. Harms $\mathrm{KL}$ and Chen $\mathrm{X}(2005)$ The $\mathrm{C}$ terminus of $\mathrm{p} 53$ family proteins is a cell fate determinant. Mol. Cell. Biol. 25: 2014-2030.

65. Palecek E, Brazdova M, Cernocka H, VIk D, Brazda V and Vojtesek B (1999) Effect of transition metals on binding of $p 53$ protein to supercoiled DNA and to consensus sequence in DNA fragments. Oncogene 18: 3617-3625.

66. Okorokov AL and Milner J (1999) An ATP/ADP-dependent molecular switch regulates the stability of p53-DNA complexes. Mol. Cell. Biol. 19: 7501-7510.

67. McLure KG, Takagi M and Kastan MB (2004) NAD+ modulates p53 DNA binding specificity and function. Mol. Cell. Biol. 24: 9958-9967.

68. Nagaich AK, Appella E and Harrington RE (1997) DNA bending is essential for the site-specific recognition of DNA response elements by the DNA binding domain of the tumor suppressor protein p53. J. Biol. Chem. 272: 14842-14849.

69. Bell S, Klein C, Muller L, Hansen S and Buchner J (2002) p53 contains large unstructured regions in its native state. J. Mol. Biol. 322: 917-927.

70. Dawson R, Muller L, Dehner A, Klein C, Kessler H and Buchner J (2003) The $\mathrm{N}$-terminal domain of p53 is natively unfolded. J. Mol. Biol. 332: 1131-1141.

71. Lee H, Mok KH, Muhandiram R, Park KH, Suk JE, Kim DH, Chang J, Sung YC, Choi KY and Han KH (2000) Local structural elements in the mostly unstructured transcriptional activation domain of human p53. J. Biol. Chem. 275: 29426-29432.

72. Lin JY, Chen JD, Elenbaas B and Levine AJ (1994) Several hydrophobic amino acids in the $p 53$ amino-terminal domain are required for transcriptional activation, binding to $\mathrm{mdm}-2$ and the adenovirus 5 E1B $55-\mathrm{kD}$ protein. Gene Dev. 8: 1235-1246.

73. Candau R, Scolnick DM, Darpino P, Ying CY, Halazonetis TD and Berger SL (1997) Two tandem and independent sub-activation domains in the amino terminus of $\mathrm{p} 53$ require the adaptor complex for activity. Oncogene 15: $807-816$
74. Chang J, Kim DH, Lee SW, Choi KY and Sung YC (1995) Transactivation ability of p53 transcriptional activation domain is directly related to the binding affinity to TATA-binding protein. J. Biol. Chem. 270: 25014-25019.

75. Zilfou JT, Hoffman WH, Sank M, George DL and Murphy M (2001) The corepressor mSin3a interacts with the proline-rich domain of p53 and protects p53 from proteasome-mediated degradation. Mol. Cell. Biol. 21: 3974-3985.

76. Zheng H, You H, Zhou XZ, Murray SA, Uchida T, Wulf G, Gu L, Tang X, Lu KP and Xiao ZX (2002) The prolyl isomerase Pin1 is a regulator of p53 in genotoxic response. Nature 419: 849-853.

77. Zacchi P, Gostissa M, Uchida T, Salvagno C, Avolio F, Volinia S, Ronai Z, Blandino G, Schneider C and Del Sal G (2002) The prolyl isomerase Pin1 reveals a mechanism to control p53 functions after genotoxic insults. Nature 419: 853-857.

78. Dornan D, Shimizu H, Burch L, Smith AJ and Hupp TR (2003) The proline repeat domain of p53 binds directly to the transcriptional coactivator p300 and allosterically controls DNA-dependent acetylation of p53. Mol. Cell. Biol. 23: 8846-8861.

79. Curtin JC and Spinella MJ (2005) p53 in human embryonal carcinoma: identification of a transferable, transcriptional repression domain in the $\mathrm{N}$ terminal region of $p 53$. Oncogene 24: 1481-1490.

80. Bond GL, Hu W and Levine AJ (2005) MDM2 is a central node in the p53 pathway: 12 years and counting. Curr. Cancer Drug Targets 5: 3-8

81. Zhang $Y$ and Xiong $Y$ (2001) A p53 amino-terminal nuclear export signal inhibited by DNA damage-induced phosphorylation. Science 292: 1910-1915.

82. Shieh S-Y, Ikeda M, Taya $Y$ and Prives C (1997) DNA damage-induced phosphorylation of p53 alleviates inhibition by MDM2. Cell 91: 325-334.

83. Chehab NH, Malikzay A, Stavridi ES and Halazonetis TD (1999) Phosphorylation of Ser-20 mediates stabilization of human p53 in response to DNA damage. Proc. Natl. Acad. Sci. USA 96: 13777-13782.

84. Dumaz N and Meek DW (1999) Serine15 phosphorylation stimulates p53 transactivation but does not directly influence interaction with HDM2. EMBO J. 18: $7002-7010$

85. Lambert PF, Kashanchi F, Radonovich MF, Shiekhattar R and Brady JN (1998) Phosphorylation of p53 serine 15 increases interaction with CBP. J. Biol. Chem. 273: 33048-33053.

86. Saito S, Goodarzi AA, Higashimoto Y, Noda Y, Lees-Miller SP, Appella E and Anderson CW (2002) ATM mediates phosphorylation at multiple p53 sites, including Ser(46), in response to ionizing radiation. J. Biol. Chem. 277: 12491-12494.

87. Mayo LD, Seo YR, Jackson MW, Smith ML, Rivera Guzman J, Korgaonkar CK and Donner DB (2005) Phosphorylation of human p53 at serine 46 determines promoter selection and whether apoptosis is attenuated or amplified. J. Biol. Chem. 280: 25953-25959.

88. Saito S, Yamaguchi H, Higashimoto Y, Chao C, Xu Y, Fornace Jr AJ, Appella $E$ and Anderson CW (2003) Phosphorylation site interdependence of human p53 post-translational modifications in response to stress. J. Biol. Chem. 278: 37536-37544.

89. Ashcroft M, Kubbutat MH and Vousden KH (1999) Regulation of p53 function and stability by phosphorylation. Mol. Cell Biol. 19: 1751-1758.

90. Thompson T, Tovar C, Yang H, Carvajal D, Vu BT, Xu Q, Wahl GM, Heimbrook DC and Vassilev LT (2004) Phosphorylation of p53 on key serines is dispensable for transcriptional activation and apoptosis. J. Biol. Chem. 279: 53015-53022.

91. Bochar DA, Wang L, Beniya H, Kinev A, Xue Y, Lane WS, Wang W, Kashanchi $F$ and Shiekhattar R (2000) BRCA1 is associated with a human SWI/SNF-related complex: linking chromatin remodeling to breast cancer. Cell 102: 257-265.

92. Lee D, Kim JW, Seo T, Hwang SG, Choi EJ and Choe J (2002) SWI/SNF complex interacts with tumor suppressor p53 and is necessary for the activation of p53-mediated transcription. J. Biol. Chem. 277: 22330-22337.

93. Hill DA, de la Serna IL, Veal TM and Imbalzano AN (2004) BRCA1 interacts with dominant negative SWI/SNF enzymes without affecting homologous recombination or radiation-induced gene activation of p21 or Mdm2. J. Cell Biochem. 91: 987-998.

94. Hsu CH, Chang MD, Tai KY, Yang YT, Wang PS, Chen CJ, Wang YH, Lee SC, Wu CW and Juan LJ (2004) HCMV IE2-mediated inhibition of HAT activity downregulates p53 function. EMBO J. 23: 2269-2280. 
regulation by ETS-1 and p53, respectively. J. Biol. Chem. 279: 52141-52149

5. Barlev NA, Liu L, Chehab NH, Mansfield K, Harris KG, Halazonetis TD and Berger SL (2001) Acetylation of p53 activates transcription through recruitment of coactivators/histone acetyltransferases. Mol. Cell 8 : 1243-1254.

96. Lill NL, Grossman SR, Ginsberg D, DeCaprio J and Livingston DM (1997) Binding and modulation of p53 by p300/CBP coactivators. Nature 387 823-827.

97. Avantaggiati ML, Ogryzko V, Gardner K, Giordano A, Levine AS and Kelly K (1997) Recruitment of p300/CBP in p53-dependent signal pathways. Cell 89 1175-1184.

98. An W, Kim J and Roeder RG (2004) Ordered cooperative functions of PRMT1, p300, and CARM1 in transcriptional activation by p53. Cell 117: 735-748.

99. Gu W, Malik S, Ito M, Yuan CX, Fondell JD, Zhang X, Martinez E, Qin J and Roeder RG (1999) A novel human SRB/MED-containing cofactor complex, SMCC, involved in transcription regulation. Mol. Cell 3: 97-108.

100. Zhang X, Krutchinsky A, Fukuda A, Chen W, Yamamura S, Chait BT and Roeder RG (2005) MED1/TRAP220 exists predominantly in a TRAP/Mediator subpopulation enriched in RNA polymerase II and is required for ER-mediated transcription. Mol. Cell 19: 89-100.

101. Xing J, Sheppard HM, Corneillie SI and Liu X (2001) p53 Stimulates TFIIDTFIIA-promoter complex assembly, and p53-T antigen complex inhibits TATA binding protein-TATA interaction. Mol. Cell Biol. 21: 3652-3661.

102. Graunke DM, Fornace Jr AJ and Pieper RO (1999) Presetting of chromatin structure and transcription factor binding poise the human GADD45 gene for rapid transcriptional up-regulation. Nucleic Acids Res. 27: 3881-3890.

103. Xiao G, White $D$ and Bargonetti $J$ (1998) p53 binds to a constitutively nucleosome free region of the mdm2 gene. Oncogene 16: 1171-1181.

104. Braastad CD, Han Z and Hendrickson EA (2003) Constitutive DNase I hypersensitivity of p53-regulated promoters. J. Biol. Chem. 278: 8261-8268.

105. Harms K, Nozell S and Chen X (2004) The common and distinct target genes of the p53 family transcription factors. Cell. Mol. Life Sci. 61: 822-842.

106. $Y u J$ and Zhang $L(2005)$ The transcriptional targets of p53 in apoptosis control. Biochem. Biophys. Res. Commun. 331: 851-858.

107. Mirza A, Wu Q, Wang L, McClanahan T, Bishop WR, Gheyas F, Ding W, Hutchins B, Hockenberry T, Kirschmeier P, Greene JR and Liu S (2003) Global transcriptional program of p53 target genes during the process of apoptosis and cell cycle progression. Oncogene 22: 3645-3654.

108. Burns TF and El-Deiry WS (2003) Microarray analysis of p53 target gene expression patterns in the spleen and thymus in response to ionizing radiation. Cancer Biol. Ther. 2: 431-443.

109. Sax JK, Stoddard A, Murphy ME, Chodosh L and El-Deiry WS (2003) Microarray expression profiling of p53-dependent transcriptional changes in an immortalized mouse embryo fibroblast cell line. Cancer Biol. Ther. 2 416-430.

110. Robinson M, Jiang P, Cui J, Li J, Wang Y, Swaroop M, Madore S, Lawrence TS and Sun $Y(2003)$ Global genechip profiling to identify genes responsive to p53-induced growth arrest and apoptosis in human lung carcinoma cells. Cancer Biol. Ther. 2: 406-415.

111. Zhu N, Gu L, Findley HW and Zhou M (2005) Transcriptional repression of the eukaryotic initiation factor $4 \mathrm{E}$ gene by wild type p53. Biochem. Biophys. Res. Commun. 335: 1272-1279.

112. Kim E, Gunther W, Yoshizato K, Meissner H, Zapf S, Nusing RM, Yamamoto H, Van Meir EG, Deppert W and Giese A (2003) Tumor suppressor p53 inhibits transcriptional activation of invasion gene thromboxane synthase mediated by the proto-oncogenic factor ets-1. Oncogene 22: 7716-7727.

113. Maiyar AC, Phu PT, Huang AJ and Firestone GL (1997) Repression of glucocorticoid receptor transactivation and DNA binding of a glucocorticoid response element within the serum/glucocorticoid-inducible protein kinase (sgk) gene promoter by the p53 tumor suppressor protein. Mol. Endocrinol. 11: 312-329.

114. Liu G, Schwartz JA and Brooks SC (1999) p53 down-regulates ER-responsive genes by interfering with the binding of ER to ERE. Biochem. Biophys. Res. Commun. 264: 359-364.

115. Maeda Y, Seidel SD, Wei G, Liu X and Sladek FM (2002) Repression of hepatocyte nuclear factor 4alpha tumor suppressor p53: involvement of the ligand-binding domain and histone deacetylase activity. Mol. Endocrinol. 16: $402-410$

116. Gu L, Zhu N, Findley HW, Woods WG and Zhou M (2004) Identification and characterization of the IKKalpha promoter: positive and negative
117. St Clair S, Giono L, Varmeh-Ziaie S, Resnick-Silverman L, Liu WJ, Padi A, Dastidar J, DaCosta A, Mattia M and Manfredi JJ (2004) DNA damageinduced downregulation of $\mathrm{Cdc} 25 \mathrm{C}$ is mediated by p53 via two independent mechanisms: one involves direct binding to the cdc25C promoter. Mol. Cell 16: 725-736.

118. Ori A, Zauberman A, Doitsh G, Paran N, Oren M and Shaul Y (1998) p53 binds and represses the HBV enhancer: an adjacent enhancer element can reverse the transcription effect of p53. EMBO J. 17: 544-553.

119. Lee KC, Crowe AJ and Barton MC (1999) p53-mediated repression of alpha-fetoprotein gene expression by specific DNA binding. Mol. Cell Biol. 19: 1279-1288.

120. Li B and Lee MY (2001) Transcriptional regulation of the human DNA polymerase delta catalytic subunit gene POLD1 by p53 tumor suppressor and Sp1. J. Biol. Chem. 276: 29729-29739.

121. Subbaramaiah K, Altorki N, Chung WJ, Mestre JR, Sampat A and Dannenberg AJ (1999) Inhibition of cyclooxygenase-2 gene expression by p53. J. Biol. Chem. 274: 10911-10915.

122. Murphy M, Ahn J, Walker KK, Hoffman WH, Evans RM, Levine AJ and George DL (1999) Transcriptional repression by wild-type p53 utilizes histone deacetylases, mediated by interaction with mSin3a. Genes Dev. 13: 2490-2501.

123. Koumenis C, Alarcon R, Hammond E, Sutphin P, Hoffman W, Murphy M, Derr J, Taya Y, Lowe SW, Kastan M and Giaccia A (2001) Regulation of p53 by hypoxia: dissociation of transcriptional repression and apoptosis from p53dependent transactivation. Mol. Cell Biol. 21: 1297-1310.

124. Ho JS, Ma W, Mao DY and Benchimol S (2005) p53-Dependent transcriptional repression of c-myc is required for $\mathrm{G} 1$ cell cycle arrest. Mol. Cell Biol. 25: 7423-7431.

125. Johnson RA, Shepard EM and Scotto KW (2005) Differential regulation of MDR1 transcription by the p53 family members. Role of the DNA binding domain. J. Biol. Chem. 280: 13213-13219.

126. Sengupta S, Shimamoto A, Koshiji M, Pedeux R, Rusin M, Spillare EA, Shen JC, Huang LE, Lindor NM, Furuichi Y and Harris CC (2005) Tumor suppressor p53 represses transcription of RECQ4 helicase. Oncogene 24: 1738-1748.

127. Chun AC and Jin DY (2003) Transcriptional regulation of mitotic checkpoint gene MAD1 by p53. J. Biol. Chem. 278: 37439-37450.

128. Wilkinson DS, Ogden SK, Stratton SA, Piechan JL, Nguyen TT, Smulian GA and Barton MC (2005) A direct intersection between p53 and transforming growth factor beta pathways targets chromatin modification and transcription repression of the alpha-fetoprotein gene. Mol. Cell Biol. 25: 1200-1212.

129. Rocha S, Martin AM, Meek DW and Perkins ND (2003) p53 represses cyclin D1 transcription through down regulation of $\mathrm{Bcl}-3$ and inducing increased association of the p52 NF-kappaB subunit with histone deacetylase 1. Mol. Cell Biol. 23: 4713-4727.

130. Gottifredi V, Karni-Schmidt O, Shieh SS and Prives C (2001) p53 downregulates $\mathrm{CHK} 1$ through p21 and the retinoblastoma protein. Mol. Cell Biol. 21: 1066-1076.

131. Lohr K, Moritz C, Contente A and Dobbelstein M (2003) p21/CDKN1A mediates negative regulation of transcription by p53. J. Biol. Chem. 278: $32507-32516$

132. Murphy M, Hinman A and Levine AJ (1996) Wild-type p53 negatively regulates the expression of a microtubule-associated protein. Genes Dev. 10: 2971-2980.

133. Venot $C$, Maratrat M, Dureuil $C$, Conseiller $E$, Bracco $L$ and Debussche $L$ (1998) The requirement for the p53 proline-rich functional domain for mediation of apoptosis is correlated with specific PIG3 gene transactivation and with transcriptional repression. EMBO J. 17: 4668-4679.

134. Li J, Tan M, Li L, Pamarthy D, Lawrence TS and Sun Y (2005) SAK, a new polo-like kinase, is transcriptionally repressed by $\mathrm{p} 53$ and induces apoptosis upon RNAi silencing. Neoplasia 7: 312-323.

135. Gridasova AA and Henry RW (2005) The p53 tumor suppressor protein represses human snRNA gene transcription by RNA polymerases II and III independently of sequence-specific DNA binding. Mol. Cell Biol. 25: 3247-3260.

136. Zhai W and Comai $L$ (2000) Repression of RNA polymerase I transcription by the tumor suppressor p53. Mol. Cell Biol. 20: 5930-5938. 
137. Budde A and Grummt I (1999) p53 represses ribosomal gene transcription. Oncogene 18: 1119-1124.

138. Stein T, Crighton D, Warnock LJ, Milner J and White RJ (2002) Several regions of $p 53$ are involved in repression of RNA polymerase III transcription. Oncogene 21: 5540-5547.

139. Crighton D, Woiwode A, Zhang C, Mandavia N, Morton JP, Warnock LJ, Milner J, White RJ and Johnson DL (2003) p53 represses RNA polymerase III transcription by targeting TBP and inhibiting promoter occupancy by TFIIIB. EMBO J. 22: 2810-2820.

140. Eichhorn $\mathrm{K}$ and Jackson SP (2001) A role for TAF3B2 in the repression of human RNA polymerase III transcription in nonproliferating cells. J. Biol. Chem. 276: 21158-21165.
141. Cairns CA and White RJ (1998) p53 is a general repressor of RNA polymerase III transcription. EMBO J. 17: 3112-3123.

142. Bourdon JC, Fernandes K, Murray-Zmijewski F, Liu G, Diot A, Xirodimas DP, Saville MK and Lane DP (2005) p53 isoforms can regulate p53 transcriptional activity. Genes Dev. 19: 2122-2137.

143. Rohaly G, Chemnitz J, Dehde S, Nunez AM, Heukeshoven J, Deppert W and Dornreiter I (2005) A novel human p53 isoform is an essential element of the ATR-intra-S phase checkpoint. Cell 122: 21-32.

144. Harms $K L$ and Chen $X$ (2006) The functional domains in p53 family proteins exhibit both common and distinct properties. Cell Death Differ. 13: 890-897. 